\title{
The biomechanical properties of the cornea in patients with systemic lupus erythematosus
}

AT Yazici, N Kara, K Yüksel, H Altinkaynak, O Baz, E Bozkurt and A Demirok

\begin{abstract}
Pupose: The purpose of this study was to compare the biomechanical properties of the cornea and intraocular pressure (IOP) between patients with systemic lupus erythematosis (SLE) and age-matched controls. Patients and Methods: In this prospective study, 30 healthy individuals (control group) and 30 patients with SLE (study group) underwent Reichert ocular response analyzer (ORA) measurements. In the right eye of each participant, the corneal hysteresis (CH), corneal resistance factor (CRF), and Goldman-related IOP (IOPg) were recorded using the ORA.

Results: Mean $\mathrm{CH}, \mathrm{CRF}$, IOPg were significantly different between groups. Mean $\mathrm{CH}$ was $10.2 \pm 0.6 \mathrm{~mm} \mathrm{Hg}$ in the study group and $11.3 \pm 1.3$ in the control group $(P=0.02)$; mean CRF was $9.7 \pm 1.1 \mathrm{~mm} \mathrm{Hg}$ and $11.9 \pm 1.5 \mathrm{~mm} \mathrm{Hg}$, respectively $(P=0.001)$. Mean IOP $_{\mathrm{g}}$ was $13.9 \pm 2.9 \mathrm{~mm} \mathrm{Hg}$ in the study group and $16.9 \pm 2.6 \mathrm{~mm} \mathrm{Hg}$ in the control group $(P=0.001)$.

Conclusion: The biomechanical properties of the cornea are altered in patients with SLE compared with normal controls. These findings should be taken into account when measuring IOP values in patients with SLE as IOP readings may be underestimated in SLE eyes. Eye (2011) 25, 1005-1009; doi:10.1038/eye.2011.99; published online 6 May 2011
\end{abstract}

Keywords: corneal hysteresis; corneal resistance factor; ocular response analyzer; systemic lupus erythematosis

\section{Introduction}

Systemic lupus erythematosus (SLE) is an autoimmune inflammatory chronic connective tissue disorder that can affect various body tissues. Although the precise mechanisms involved in the pathogenesis of SLE are not well understood, the production of autoantibodies and immune complex-mediated inflammation are the primary cause of tissue damage in patients with SLE. It most commonly affects the joints, skin, and kidneys, but the eyes may also be involved. Although the most common ocular findings include dry eye and retinal vascular changes, corneal changes can occur, such as recurrent corneal erosions, stromal infiltration, corneal scarring, peripheral ulcerative keratitis, corneal edema, and deep interstitial keratitis. ${ }^{1-5}$

The corneal stroma is responsible for the mechanical and refractive properties of the cornea. The anterior part of the corneal stroma is thought to be responsible for corneal shape stability. ${ }^{6}$ Changes in the properties of the corneal stroma occur because of advancing age, corneal pathology such as keratoconus, systemic diseases such as keratoconus, and altered hydration, in which a loss of stromal lamellae organization modifies the corneal biomechanical properties. We hypothesize that, because of the rich connective tissue in the cornea, the biomechanical properties of the cornea are especially vulnerable to connective tissue diseases (CTDs).

Corneal biomechanical evaluation may be valuable for preoperative screening of refractive surgery candidates, avoiding misinterpretation of the intraocular pressure (IOP), and helping to differentiate between healthy and abnormal corneas. $^{.-9}$

The ocular response analyzer (ORA) for in vivo assessment of corneal biomechanics was recently introduced by Reichert (Reichert Ophthalmic Instruments, Buffalo, NY, USA). It allows for the measurement of IOP, corneal hysteresis $(\mathrm{CH})$, and corneal resistance factor (CRF). Corneal hysteresis, which is calculated as
Beyoglu Eye Research And Training Hospital, Istanbul, Turkey

Correspondence: N Kara, Department of Ophthalmology, Kartaltepe Mh, Akın Sk. Akın Apt. No: 8/14 Bakırköy/lstanbul, Beyoglu 34001, Turkey Tel: + 900505866 6830; Fax: +9048798798755 E-mail:dr.necipkara@ gmail.com

Received: 3 December 2010 Accepted in revised form: 17 March 2011 Published online: 6 May 2011 
the difference between the two pressure values at two applanation processes, is related to the viscoelastic behavior of the corneal tissue. The CRF, which is calculated as a linear function of the two pressures associated with the two applanation processes, is an indicator of overall corneal resistance. ${ }^{6}$

In the present study, we investigated the biomechanical properties of the cornea and IOP in patients with SLE and age-matched controls.

\section{Materials and methods}

This prospective, cross-sectional, and comparative study was performed at the Beyoglu Eye Education and Research Hospital and Haseki Education and Research Hospital. The study followed the tenets of the Declaration of Helsinki and was approved by the ethics committee of the Beyoglu Eye Research and Education Hospital. Written, informed consent was obtained from all of the patients. Patients were evaluated from February 2009 to April 2010.

The patients were divided into two groups: normal cases (control group) and cases with SLE (study group). The study group comprised patients with SLE referred to us from the Department of Rheumatology. The agematched control group comprised healthy individuals examined at the Department of Rheumatology and in whom CTDs were excluded.

Patients with ocular disease other than dry eye, previous ocular surgery, past history of ocular inflammatory disease or glaucoma, use of any topical medication except for artificial tears, diabetes, and pregnancy were excluded from the study.

Each clinical examination consisted of best corrected visual acuity using a Snellen chart, IOP measurement using the Goldmann applanation tonometer, biomicroscopy of the anterior segment, dilated fundus examination, and central corneal thickness (CCT) measured with ultrasound pachymetry. Study participants also underwent axial length (AL) measurements with the IOL Master (Carl Zeiss Meditech, AG, Jena, Germany). Patients with an AL greater than $24 \mathrm{~mm}$ and refractive errors greater than 3D spherical and 1D cylindrical were excluded from the study.

Three ORA measurements were performed in all patients by an experienced clinician while the patient was sitting comfortably in a chair located in a special room. Three good-quality (symmetric, well-defined inward, and outward applanation spike high) measurements were obtained for each eye and the mean values of each parameter were used for analysis. The clinician discarded the poor-quality applanation signals (atypical applanation spikes or asymmetric signals). The IOP measurements were performed by another clinician with the same applanation tonometer at least 20 min after ORA measurements were taken. Both clinicians were masked in terms of study group. Also, other measurements, including AL and CCT measurements, were performed by an experienced technician.

\section{Statistical analysis}

All statistical tests were performed using SPSS (Statistical Package for the Social Sciences; SPSS Inc., Chicago, IL, USA) version 16 . The normality of the data was confirmed using the Kolmogorov-Smirnov test $(P>0.05)$. One-way analysis of variance test was used to compare variables between groups. Pearson's correlation was used to examine the relationships among the measured variables. A $P$-value of $<0.05$ was considered significant.

\section{Results}

This study included 30 healthy subjects and 30 patients with SLE. The patient characteristics of the two groups of subjects are shown in Table 1 . There were no statistically significant differences between the two groups with regard to age and sex distributions. The mean duration of SLE was $9.9 \pm 3.2$ years.

Table 2 summarizes the clinical measurements of both groups. Mean $\mathrm{CH}$ and CRF values in eyes with SLE were significantly lower than those in age-matched controls.

The correlation analysis was performed between CCT, $\mathrm{AL}$, age, duration of disease, and $\mathrm{CH}-\mathrm{CRF}$ values. In the study group, the $\mathrm{CH}$ and $\mathrm{CRF}$ values were significantly associated with CCT ( $r=0.641, P=0.001$ and $r=0.629$, $P=0.002$, respectively). The duration of disease, age and $\mathrm{AL}$ were not associated $\mathrm{CH}-\mathrm{CRF}$ values. In the control group, the $\mathrm{CH}$ and $\mathrm{CRF}$ values were also significantly associated with CCT $(r=0.336, P=0.029$ and $r=0.503$, $P=0.001$, respectively). Axial length and age were not associated with $\mathrm{CH}-\mathrm{CRF}$ values.

The mean IOP value measured with the Goldmann applanation tonometer, and mean corneal-compensated

Table 1 Demographic characteristic of patients

\begin{tabular}{lccc}
\hline Variable & Control group & Study group & P-value \\
\hline Eyes $(N)$ & 30 & 30 & \\
Gender $(N)$ & & & \\
$\quad$ Female & 28 & 28 & \\
$\quad$ Male & 2 & 2 & \\
Age, years & & & \\
$\quad$ Mean \pm SD & $45.6 \pm 2.8$ & $45.1 \pm 3.3$ & $0.6^{\mathrm{a}}$ \\
$\quad$ Range & $(41-51)$ & $(39-50)$ & \\
\hline
\end{tabular}

${ }^{a}$ Independent samples $t$-test. 
Table 2 Study parameters of the study and control group

\begin{tabular}{|c|c|c|c|}
\hline Variable & Control & SLE & P-value \\
\hline \multicolumn{3}{|l|}{$\mathrm{CH}, \mathrm{mm} \mathrm{Hg}$} & \multirow[t]{3}{*}{0.02} \\
\hline Mean \pm SD & $11.3 \pm 1.3$ & $10.2 \pm 0.6$ & \\
\hline Range & $(9.6-13.8)$ & $(9.2-11.6)$ & \\
\hline \multicolumn{3}{|l|}{$C R F$} & \multirow[t]{3}{*}{0.001} \\
\hline Mean \pm SD & $11.9 \pm 1.5$ & $9.7 \pm 1.1$ & \\
\hline Range & $(9.8-14.1)$ & $(7.8-11.4)$ & \\
\hline \multicolumn{3}{|l|}{$\mathrm{IOPcc}, \mathrm{mm} \mathrm{Hg}$} & \multirow[t]{3}{*}{0.2} \\
\hline Mean \pm SD & $15.8 \pm 2.3$ & $14.8 \pm 2.5$ & \\
\hline Range & $(10.3-21.2)$ & $(9.5-21.1)$ & \\
\hline \multicolumn{3}{|l|}{$I O P g, m m ~ H g$} & \multirow[t]{3}{*}{0.001} \\
\hline Mean \pm SD & $16.9 \pm 2.6$ & $13.9 \pm 2.9$ & \\
\hline Range & $(11.8-22.4)$ & $(7.6-20.6)$ & \\
\hline \multicolumn{3}{|l|}{$I O P_{G A T}, m m H g$} & \multirow[t]{3}{*}{0.1} \\
\hline Mean \pm SD & $15.5 \pm 3.2$ & $13.9 \pm 3.4$ & \\
\hline Range & $(11-23)$ & $(8-23)$ & \\
\hline \multicolumn{3}{|l|}{$C C T, \mu m$} & \multirow[t]{3}{*}{0.4} \\
\hline Mean \pm SD & $560 \pm 36$ & $551 \pm 16$ & \\
\hline Range & $(506-632)$ & $(516-596)$ & \\
\hline \multicolumn{3}{|l|}{$A L, m m$} & \multirow[t]{3}{*}{0.50} \\
\hline Mean \pm SD & $23.1 \pm 0.8$ & $22.9 \pm 0.8$ & \\
\hline Range & $(22.2-23.55)$ & (21.8-23.58) & \\
\hline
\end{tabular}

Abbreviations: $\mathrm{AL}$, axial length; $\mathrm{CCT}$, central corneal thickness; $\mathrm{CH}$, corneal hysteresis; CRF, corneal resistance factor; IOPcc, cornealcompensated intraocular pressure; IOPg, Goldmann-related intraocular pressure; $\mathrm{IOP}_{\mathrm{GAT}}$, IOP value measured with the Goldmann applanation tonometer; SLE, systemic lupus erythematosus.

${ }^{\mathrm{a} O n e-w a y ~ a n a l y s i s ~ o f ~ v a r i a n c e ~ t e s t . ~}$

IOP value measured with ORA were lower in eyes with SLE, but the difference was not statistically significant between the two groups $(P>0.05)$. The mean Goldmann-related IOP (IOPg) value measured with the ORA, however, was significantly lower in eyes with SLE than in controls $(P=0.001)$.

\section{Discussion}

Corneal characteristics in ocular or systemic diseases have been described using histological diagnostic techniques, corneal topographic maps, in-vivo confocal microscopy, and CCT measurements. Reichert recently introduced the ORA for measurements of the corneal biomechanical properties. The role of corneal biomechanical properties is important in keratorefractive surgery, IOP measurement, and the development, progression, and diagnosis of ocular diseases, such as keratoconus and glaucoma. ${ }^{10,11}$
In the present study, corneal biomechanical properties such as $\mathrm{CH}$ and the CRF were measured using the ORA. These properties were compared between patients with SLE and healthy individuals. The results of our study indicate that the $\mathrm{CH}, \mathrm{CRF}$, and IOPg in eyes with SLE were significantly lower than those in healthy eyes.

Healthy human corneal stroma, which is responsible for the mechanical and refractive properties of the cornea, is composed mainly of heterotypic type I collagen. ${ }^{7}$ Although the precise mechanism that maintains corneal shape has not yet been determined, the specific architecture of the corneal stroma is thought to be responsible for the maintenance of corneal shape. ${ }^{12}$

The pathology of CTDs is suggested to be a local antigen-antibody reaction that triggers a number of biochemical and cellular responses, resulting in the lysis of the corneal collagen and corneal thinning. ${ }^{13}$ SLE is a chronic inflammatory connective tissue disorder that affects many organs. It mostly affects people in between 30 and 50 years of age. The pathogenesis of SLE is complex and not well understood. The development of SLE may be due to genetic factors, environmental factors, and hormonal factors. Autoantibodies seem to have a major role in the pathogenesis of SLE. These autoantibodies cause tissue damage by forming immune complexes and activating the complement system or by a direct pathological effect. Immune complex deposition occurs in blood vessels of the conjunctiva, retina, choroid, sclera, ciliary body, as well as in the basement membranes of the ciliary body and cornea. Although corneal involvement in SLE is rare, there are reports of epitheliopathy, keratoconjunctivitis sicca, superficial punctate keratitis, filamentary keratitis, structural disruption of the stroma, corneal scarring, peripheral ulcerative keratitis, corneal edema, and deep interstitial keratitis. $^{1-4}$

The biomechanical properties of the cornea measured with the ORA in patients with a CTD are not widely reported in the literature. Prata $e \mathrm{al}^{8}$ reported that patients with rheumatoid arthritis present with lower $\mathrm{CH}$ values and lower IOP values than age-matched controls. Emre $e t ~ a l^{14}$ however, investigated corneal biomechanical properties in patients with scleroderma. The mean CRF and IOPg values of patients with scleroderma were higher than those of age-matched healthy controls. In the present study, patients with SLE had lower CH and CRF values compared with age-matched controls. The correlation analyses showed $\mathrm{CH}$ and $\mathrm{CRF}$ decreasing with decreasing CCT in the study group $(r=0.641$ and $r=0.629$, respectively) and control group $(r=0.336$ and $r=0.503$, respectively). However, duration of disease, age, and $\mathrm{AL}$ were not associated with $\mathrm{CH}$ and $\mathrm{CRF}$ values in both groups. 
Failure to provide an early and definitive diagnosis of elevated IOP could delay treatment; therefore, prompt diagnosis and treatment are very important for preventing irreversible vision loss. ${ }^{15}$ More advanced screening tools are needed for the early detection of glaucoma. Low $\mathrm{CH}$ is a weak independent risk factor for glaucomatous damage. ${ }^{15,16}$ Gold Applanation Tonometry is the current gold standard for measuring IOP. Up to now, CCT was the only available parameter to correlate IOP measurements by applanation in different corneas. ${ }^{17,18}$ Various studies have demonstrated that IOP measured by the applanation tonometer does not always give a true reading. ${ }^{19-21}$ To date, the literature suggests that the corneal biomechanics are important, and help with the assessment of the accuracy of IOP. ${ }^{22,23}$ The ORA measurements in this study showed that the SLE patients had significantly lower IOPg values in eyes of patients with SLE than in controls. The lower IOPg values of SLE patients may be associated with decreased biomechanical properties (viscoelasticity and elasticity) of the cornea. These results show that ORA measurements may be important when trying to correct IOP measurements in affected cornea by connective tissue disorders such as SLE.

Performing ocular surgery such as corneal excimer laser may lead to some complications, even after uneventful surgery, because of the unpredictable nature of the stromal wound-healing process. ${ }^{24,25}$ After uneventful cataract surgery, sterile corneal ulceration, corneoscleral melting, and peripheral sterile ulcerative keratitis have been reported in patients with CTDs. ${ }^{26,27}$ Also, several complications such as stromal haze, corneal melting, ulceration, and poor wound healing have been reported after successful laser in situ keratomileusis in patients with CTDs. ${ }^{28,29}$ A significant decrease in the IOP and biomechanical properties such as $\mathrm{CH}$ and CRF has been reported after laserassisted in situ keratomileusis. ${ }^{30}$ Flap creation and corneal thinning caused by laser ablation leads to corneal weakening. ${ }^{31,32}$ Corneal weakness could lead to corneal ectasia following refractive surgery. On the other hand, a recent study demonstrated that the SLE patients with controlled dry eye and no active systemic symptoms did well after refractive surgery. Further biomechanical and topographic studies need to be carried out to establish the effect of corneal surgeries on corneal biomechanical parameters in patients with SLE.

In conclusion, patients with SLE present with lower $\mathrm{CH}$ and CRF values, and lower IOPg readings measured with the ORA than age-matched controls. These corneal biomechanical properties should be taken into account when determining IOP values and planning corneal refractive surgery for these patients.
Summary

What was known before

- We do not know the corneal biomechanical properties in patients with systemic lupus erythematosus.

What this study adds

- Systemic lupus erythematosus affects the corneal biomechanical properties such as corneal hysteresis and corneal resistance factor.

\section{Conflict of interest}

The authors declare no conflict of interest.

\section{Disclaimer}

The manuscript has not been previously evaluated or rejected in any form by another journal. No financial support was received.

\section{References}

1 Davies JB, Rao PK. Ocular manifestations of systemic lupus erythematosus. Curr Opin Ophthalmol 2008; 19: 512-518.

2 Foster CS, Yes M. Corneal manifestations of Graves' disease, the acquired connective tissue disorders and systemic vasculitis. Int Ophthalmol Clin 1986; 26: 131-157.

3 Reeves JA. Keratopathy associated with systemic lupus erythematosus. Arch Ophthalmol 1965; 74: 159-160.

4 Gold DH, Morris DA, Henkind P. Ocular findings in systemic lupus erythematosus. $\mathrm{Br} J$ Ophthalmol 1972; 56 : 800-880.

5 Sivaraj RR, Durrani OM, Denniston AK, Murray PI, Gordon C. Ocular manifestations of systemic lupus erythematosus. Rheumatology 2007; 46: 1757-1762.

6 Luce DA. Determining in vivo biomechanical properties of the cornea with an ocular response analyzer. J Cataract Refract Surg 2005; 31: 156-162.

7 Fontes BM, Ambrósio Jr R, Jardim D, Velarde GC, Nosé W. Corneal biomechanical metrics and anterior segment parameters in mild keratoconus. Ophthalmology 2010; 117: 673-679.

8 Prata TS, Sousa AK, Garcia Filho CA, Doi LM, Paranhos Jr A. Assessment of corneal biomechanical properties and intraocular pressure in patients with rheumatoid arthritis. Can J Ophthalmol 2009; 44: 602.

9 Goldich Y, Barkana Y, Gerber Y, Rasko A, Morad Y, Harstein $\mathrm{M}$ et al. Effect of diabetes mellitus on biomechanical parameters of the cornea. J Cataract Refract Surg 2009; 35: 715-719.

10 Glass DH, Roberts CJ, Litsky AS, Weber PA. A viscoelastic biomechanical model of the cornea describing the effect of viscosity and elasticity on hysteresis. Invest Ophthalmol Vis Sci 2008; 49: 3919-3926.

11 Touboul D, Roberts C, Kérautret J, Garra C, Maurice-Tison S, Saubusse E et al. Correlations between corneal hysteresis, intraocular pressure, and corneal central pachymetry. J Cataract Refract Surg 2008; 34: 616-622.

12 Muller LJ, Pels E, Vrensen GFJM. The specific architecture of the anterior stroma accounts for the maintenance of corneal curvature. Br J Ophthalmol 2001; 85: 437-443. 
13 Hyams SW, Kar H, Neumann E. Blue sclerae and keratoglobus. Ocular signs of a systemic connective tissue disorder. Br J Ophthalmol 1969; 53: 53-58.

14 Emre S, Kayikcioglu O, Ates H, Cinar E, Inceoǧlu N, Yargucu $\mathrm{F}$ et al. Corneal hysteresis, corneal resistance factor and intraocular pressure measurement in patients with scleroderma using the reichert ocular response analyzer. Cornea 2010; 29: 628-631.

15 Kass MA, Heuer DK, Higginbotham EJ, Johnson CA, Keltner JL, Miller JP et al. The Ocular Hypertension Treatment Study: a randomized trial determines that topical ocular hypotensive medication delays or prevents the onset of primary open-angle glaucoma. Arch Ophthalmol 2002; 120: 701-713.

16 Congdon NG, Broman AT, Bandeen-Roche K, Grover D, Quigley HA. Central corneal thickness and corneal hysteresis associated with glaucoma damage. Am J Ophthalmol 2006; 141: 868-875.

17 Brandt JD, Beiser JA, Gordon MO, Kass MA, Ocular Hypertension Treatment Study (OHTS) Group. Central corneal thickness and measured IOP response to topical ocular hypotensive medication in the Ocular Hypertension Treatment Study. Am J Ophthalmol 2004; 138: 717-722.

18 Brandt JD. Corneal thickness in glaucoma screening, diagnosis, and management. Curr Opin Ophthalmol 2004; 15 85-89.

19 Doughty MJ, Zaman ML. Corneal thickness and its impact on intraocular pressure measures. A review and metaanalysis approach. Surv Ophthalmol 2000; 44: 367-408.

20 Ehlers N, Branson T, Sperling S. Applanation tonometry and corneal thickness. Acta Ophthalmol 1975; 53: 34-43.

21 Shah S, Chatterjee A, Mathai M, Kelly SP, Kwartz J, Henson $\mathrm{D}$ et al. Relationship between corneal thickness and measured intraocular pressure in a general ophthalmology clinic. Ophthalmology 1999; 106: 2154-2160.
22 Liu J, Roberts CJ. Influence of corneal biomechanical properties on intraocular pressure measurement: quantitative analysis. J Cataract Refract Surg 2005; 31: 146-155.

23 Harada Y, Naoi N. Corneal elasticity as a measure of intraocular pressure: a controlled clinical examination. Kobe J Med Sci 2004; 50: 141-152.

24 Seiler T, Wollensak J. Complications of laser keratomileusis with excimer laser (193 nm). Klin Monastabl Augenheilkd 1992; 200: 648-653.

25 Pouliquen Y, Hanna K, Waring G, Savoldelli M. Is there a future for the excimer laser in refractive surgery?. Bull Acad Natl Med 1990; 174: 275-287.

26 Maffett MJ, Johns KJ, Parrish CM, Elliott JH, Glick AD, O'Day DM. Sterile corneal ulceration after cataract extraction in patients with collagen vascular disease. Cornea 1990; 9: 279-285.

27 Mamalis N, Johnson MD, Haines JM, Teske MP, Olson RJ. Corneo-scleral melt in association with cataract surgery and intraocular lenses: a report of four cases. J Cataract Refract Surg 1990; 16: 108-115.

28 Cua IY, Pepose JS. Late corneal scarring after photorefractive keratectomy concurrent with development of systemic lupus erythematosus. J Refract Surg 2002; 18: 750-752.

$29 \mathrm{Li} \mathrm{Y,} \mathrm{Li} \mathrm{HY.} \mathrm{Analysis} \mathrm{of} \mathrm{clinical} \mathrm{characteristics} \mathrm{and} \mathrm{risk}$ factors of corneal melting after laser in situ keratomileusis. Zhonghua Yan Ke Za Zhi 2005; 41: 330-334.

30 Ortiz D, Piñero D, Shabayek MH, Arnalich-Montiel F, Alió JL. Corneal biomechanical properties in normal, post-laser in situ keratomileusis, and keratoconic eyes. J Cataract Refract Surg 2007; 33: 1371-1375.

31 Dupps Jr WJ. Biomechanical modeling of corneal ectasia. J Refract Surg 2005; 21: 186-190.

32 Guirao A. Theoretical elastic response of the cornea to refractive surgery: risk factors for keratectasia. J Refract Surg 2005; 21: 176-185. 